DOI: $10.1515 / \mathrm{aa}-2017-0006$

\title{
Cognitive distortion, translation distortion and poetic distortion as semiotic
}

\section{shifts}

Sofia Osimo, Bruno Osimo

Sofia Osimo was born in Milan, Italy, in 1989. She is a psychologist and is pursuing a $\mathrm{PhD}$ in cognitive neuroscience at the International School for Advanced Studies in Trieste, Italy.

Bruno Osimo was born in Milan, Italy, in 1958. He has a $\mathrm{PhD}$ in translation semiotics under the supervision of Peeter Torop. He teaches translation and translation science at the Civica Scuola Interpreti e Traduttori "Altiero Spinelli". He translates into Italian and has edited books by Torop, Popovič, Lyudskanov, Revzin-Rosenzweig, Jakobson and Lotman. He has published the most widespread translation handbook in Italy and papers on translation with a semiotic approach. Since 2000 he has been writing for the journal Sign Systems Studies.

\begin{abstract}
Both interlingual translation shifts and poetic production can be seen from a semiotic perspective in terms of mental filtering. The shared ground of the three processes - cognition, translation, versification - is to be found in the semiotic perspective: signs (prototext, reality, perception) are interpreted and worked through (mind, interpretants, cognition) and give as an output an object (metatext, poem, worldview). By trying to classify the shifts resulting from such processes - distortions - with a semiotically shared grid of categories, the hypothesis is that the categories themselves - already existing within the separate fields - can be reciprocally fine-tuned. The very notion of "shift" - derived from translation criticism, and in particular from the prototext-metatext comparison - becomes in this hypothesis a connection transforming the shifts possible in the other mentioned fields into mutual benchmarks.
\end{abstract}

\section{Premises}

The present paper stems from the hypothesis that versification, interlingual translation, and cognition can be semiotically considered as mental shifts between sign, interpretant and object. Both in translation and in versification a prototext, an experience (sign) is elaborated in the mind of the writer, translator etc. (interpretant), producing a metatext, a poem (object) in a way similar to how any percept (sign) is elaborated by a person's mind (interpretant) producing a worldview (object): the input-sign is filtered and distorted in idiosyncratic ways (interpretant) that are partly conscious and partly unconscious.

In translation, the notion of "shift" is used to describe the difference in reception between the prototext and the metatext. Here the notion is useful for a view of translation criticism 
based not on linguistic categories - which are not necessarily significant as far as the impact of a text's sense on a culture is concerned - but on semiotic categories. Translation shifts are measured on the supposed sense impact of a text on a culture.

Given this view, other processes having a similar pattern come to mind. One is cognition, in which a percept (sign) is interpreted by a subject's (interpretant) mind, producing a view (object), a part of the subject's worldview. Therefore, we thought that the model of translation shifts could be applied to cognition as well. Isn't translation a form of mediating cognition and reformulation?

A special mention is merited by the coverage of poetry. In poetry there seems to be a continuum between rumination, inner speech, and poetic production: "there may be multiple layers of parallel thinking in the subterranean region of the unconscious and they may all contribute to the creative process. Such associate thinking may be more symbolic, condensed and highly loaded with meanings. There may be a continuum between co-thinking, automatic thoughts and inner speech. Associate thinking may initiate and supplement inner speech" (Pandarakalam, 2017, p. 174). Therefore we can assume that in poetry some traits of inner speech (Vygotsky, 1962) remain included in the text. This means that many features of a text that in other genres are considered a flaw, in poetry abound.

In the case of translation, the result of the filtering action is the metatext. In the case of versification, the result is the poem. From the psychologist's point of view the result is a worldview, a specific reading of inner and/or outer reality.

\subsection{Why poetry is a translation process and translation is a mental process}

In Thinking and Speech (1934), Lev Vygotsky defines inner language as a nonverbal, nondiscrete language. If this is true, then every act of reading/listening is an intersemiotic translation from verbal into mental (from discrete to nondiscrete), and every act of writing/speaking is an intersemiotic translation process from mental into verbal (from nondiscrete into discrete).

In "On Linguistic Aspects of Translation" (1959) Jakobson speaks of intersemiotic, intralingual, and interlingual translation, implicitly inviting researchers to consider the three types of process within translatology. In the light of Vygotsky's view, Jakobson not only refers to film adaptations or poems inspired by pictures, and so on, but also to the intrinsically intersemiotic character of any simply interlingual translation process (translation proper) (Osimo, 2017).

In Teória umeleckého prekladu [Theory of artistic translation] (1975) Popovič suggests the 
use of "prototext" and "metatext" (instead of "original" and "translation") so that a scientific definition can be given of the translation process. In this way, any act of second-degree communication - including intertextual references - is a kind of translation process and produces a metatext.

In Total'nyj perevod ['Total translation'] (1995), Torop suggest widenening even more the scope of Popovič's translatology to metatexts meant as paratexts, such as critical apparatus, editorial structure, reviews, summaries, footnotes, and any text that can be complementary to a main text.

A poem - if one wants to see it in that way - follows the same pattern of secondary-degree communication (it is a secondary modelling system; Lotman 1970): given an aspect of reality (prototext) perceived by the author's mind (interpretant), it is transformed into a poem (metatext) where you can identify a variant, an invariant, a gain, and a loss. Along the same lines a cognitive distortion is a process in which a piece of reality (prototext) is perceived in a given way (metatext) according to a pattern (bias, neurosis, etc.) providing for 1) a variant, 2) an invariant, 3) a gain, and 4) a loss. (In psychosis there may be little or no invariant, therefore it cannot be fully considered here.)

What translation, poetry and disorder share is the notion of "distortion". If we could find a synthetic view, a shared definition of these three types of translation processes, the three different contexts and ways in which they are actualized would be a precious reciprocal benchmark.

One of the purposes of this paper is to find categories of shifts that fit in the three different contexts. The strength of each definition is increased by the very fact that it supposedly also fits in the other two contexts that in principle share the same pattern of the translation process.

\subsection{Definition of translation process}

A translation is defined as a process where a text (called "prototext") is transformed into another text (called "metatext"), in a way that there are 1) a variant, 2) an invariant, 3) a gain, and 4) a loss. Here the distortion affects the points 1, 3, 4 .

\subsection{Definition of cognitive distortion}

Perception is a selection and representation process of species-specifically useful features, in which the nervous system of a given species has developed to create a representation of salient environmental features. The form of the resulting percept is arbitrarily species-specific and, even though some types of representations are more informative than others, no type can 
be considered the most "faithful" - whatever this may mean - representation of reality. For example, human vision produces coloured percepts while other animals' percepts, such as cats', translate the visible wavelength of light on a continuous scale that is not fragmented into colours. Even if it might seem that one of the two representations is better than the other one, neither can be considered more or less distorted than the other. Light, in fact, has a wide spectrum of wavelengths, but colours only exist in some species-specific decodings.

On these premises, we can say that any percept and any representation is a distortion; the word "distortion" is not here used in a derogatory sense. When we speak of "reality", then, we refer simply to the most frequent, common representation of the environment.

Cognitive distortions are irrational, unavoidable thought patterns that cause individuals to perceive reality in a subject-specific way. Cognitive distortions tend to interfere with the way a person perceives something. The way a person feels intervenes with how they think. If we use the grid of the definition of "translation process" (see next paragraph) to describe cognitive distortion, we get:

A cognitive distortion may be defined as a process where a text (called "reality") is transformed into another text (called "individual perception of reality"), in a way that there are 1) a variant (misperception), 2) an invariant (perception), 3) a gain (overperception), and 4) a loss (loss of awareness). Here the distortion affects the points 1, 3, 4 .

\subsection{Definition of poetry}

Many definitions have been made of the notion of "poetry". Since poetry is considered in many cultures as the farthest field from science, it is difficult to find a scientific definition. Charles Sanders Peirce was inclined to think that poets are fine observers, and that poems are a "true" description of reality: "I hear you say: 'All that is not fact; it is poetry'. Nonsense! Bad

poetry is false, I grant; but nothing is truer than true poetry. And let me tell the scientific men that the artists are much finer and more accurate observers than they are, except of the special minutiae that the scientific man is looking for" (Peirce, 1:315).

Poetry is a sort of psychology, according to Peirce, in the sense that it is a dependable tool to describe feelings as an interpersonal phenomenon: "The generalization of sentiment can take place on different sides. Poetry is one sort of generalization of sentiment, and in so far is the regenerative metamorphosis of sentiment. But poetry remains on one side ungeneralized, and to that is due its emptiness" (Peirce, 1:676).

Hudson Maxim also speaks of poetry in terms of description of reality: "Poetry is the expression of imaginative thought by means only of the essentials to the thought, conserving 
energy for thought-perception, to which end all animate, inanimate and intangible things may assume the properties and attributes of tangible, living, thinking and speaking things, possessing the power of becoming what they seem, or of transfiguration into what they suggest" (Maxim, 1910, p. 359).

Jakobson is perhaps the first to find a scientific definition for poetry. He realizes that the ways to connect words in a discourse can be of two rather different kinds: the usual one, through syntactic rules; $[. .$.$] "The poetic function projects the principle of equivalence from$ the axis of selection into the axis of combination. Equivalence is promoted to the constitutive device of the sequence" (Jakobson, 1960, p. 358).

If we use the grid of the definition of "translation process" (see 0.1 ) to describe poetry, we get: poetry may be defined as a process where a text (called "poet's perceived reality") is transformed into another text (called a "poem"), in a way that there are 1) a variant (misperception), 2) an invariant (perception), 3) a gain (overperception), and 4) a loss (loss of awareness). Here the distortion affects the points 1, 3, 4 .

\section{Why poetry?}

For our reflection, we needed a form of creativity that potentially shares something with translation and with mental distortion. Among the forms of writing, poetry seems the most prone to emotional overflow: "For poets, their work is often their feelings" (Thomas and Duke, 2007, p. 216). We noticed that many studies focus on the correlation between poetry and mental illness and, particularly, between poetry and suicide, the so-called "Sylvia Plath effect": "the types of people who are drawn to poetry, the inability of poetry to assuage mental illness, the impact that the field has on poets" (Kaufman and Baer, 2002, p. 273).

There seems to be a correlation also between poetry and mental illness: "Authors suffered from schizophrenia and bipolar disorder more than twice as often as controls. Authors were also more likely [...] to commit suicide" (Kyaga et al., 2012, p. 4). There might be a two-way link between poetry and mental illness: people with mental disorders use poetry as a tool for self-expression, and poets tend to be mentally ill owing to their borderline activity. "[...] the nature and style of poetry draws people who may be more likely to be unstable" (Kaufman and Baer, 2002, p. 273).

Poets tend to try to use their activity as a palliative to alleviate their heavy mood states, "working through confusing and upsetting thoughts and feelings through a meaning-making process" (Kaufman and Sexton, 2006, p. 274).

It seems, however, that such an activity - as opposed to that of other creative writers - 
doesn't provide for the expected results: "poets may not receive this benefit as strongly because of the absence of a narrative in most poems" (Kaufman and Sexton, 2006, p. 278).

It would seem that writing poetry is an activity that pushes people toward the border between selection and combination, to use Jakobson's terminology. "The tendency toward being more expressive may make one more prone to illness" (Kaufman and Baer, 2002, p. 274). While the "standard" person uses language as an invisible tool, partially or totally ignoring metalanguage, and the textologist shifts from language to metalanguage and back in a rational way when that is necessary to make scientific observations about text, poets feel the constant temptation to let themselves be carried away by combination, by metalanguage, by logical links that look more like the ones between sign and interpretant, or between interpretant and object, than by links like the more "rational" ones between sign and object: "divergent thinking or the capacity for broad associative thinking has since long been considered fundamental to creativity" (Kyaga et al., 2012, p. 7).

Poets also seem to be on the border, from a clinical point of view, between mania and depression: "Increasing evidence suggests a possible genetic link between bipolar depression and creativity (Jamison, 1993), while such a connection is not suspected with unipolar depression. Likewise, evidence also suggests higher rates of bipolar disorder in poets than in writers (Jamison, 1989)" (Thomas and Duke, 2007, p. 217). Therefore, typically poets with mental disorders are not simply depressed, they are often bipolar.

There seems to be a different quality to the kind of thought that is typical for poets "Divergent thinking involves different, partly correlated, indices (e.g., fluency or quantity of ideas, flexibility or categories of ideas, and originality or the unusualness of ideas)" (Kyaga et al., 2012, p. 7).

The poet is someone who redescribes reality in a fresh way, to let emotional content pass while changing form, which is why we thought it would be interesting to make poets stand for creative mediators between perceived reality (input) and their poems (output).

\section{Distortions in translation, psychology and poetry}

An existing grid of translation shifts (Osimo, 2013) was used as a basis to write the present section. In the process of adapting the Valutrad grid to the purposes of this paper, some categories were eliminated and some were merged. For the remaining ones, a homologue was searched for in the fields of psychology and poetry. Here is the result of our reasoning.

\subsection{Relationship distortions}

In this macrogroup, distortions have to do with relationships of different kinds: of the text 
with itself (intratext, cacophony); of the text with other texts by the same author (author's style); of the text with other texts (intertext); of the text with a different culture (realia); of the text with the internal narrator's emotions (cadence, syntactic emphasis); of the internal narrator or a character with an object or character (deixis); and of the text with its reader (register, type of text, addressee).

\subsubsection{Intratext, intertext, realia and cacophony}

\subsubsection{Intratext, cacophony, intertext and realia in psychology}

In psychology, every patient can repeat, consciously or unconsciously, the same word at different times so as to create in the psychologist's mind a network of inner links to the patient's discourse. Realizing the existence of such intratexts and strategically making the patient aware of them can be a therapeutic technique to uncover the link between different parts of the patient's mind (memories, traumas, affects, and so on). When the random collocation deriving from translation produces cacophony, the problem is similar even if from a different perspective. The same goes for references to outer sources (external texts, external objects - realia - and so on), that have a definite sense in the person's worldview.

\subsubsection{Intratext, intertext and realia in translation}

In translation, repetitions and internal links to other parts of a given text are a very important feature. They make up the structure of the text. Some translation schools simplify the question by simply teaching to avoid repetitions, substituting them with so-called "synonyms". Such a simplification is unacceptable in other schools. On the other hand, this may be a good principle if you have to deal with sloppy prototexts, written by sloppy authors, who repeat words or expressions only out of lack of time, ability, etc. In high-quality text, repetitions, by contrast, are a common expressive device and when translating they can be usefully reproduced in the metatext. Semantic focusing on given subjects can result in repetitions of words that are the same or have similar semantic properties. The translators are given a network of inner links, and their mission is to reproduce that network in the metatext. The same goes for references to outer sources (external texts, external objects - realia - and so on), that in the optimal version are preserved intact. From a psychological point of view, the question is different if translators produce shift because they feel they have to modify the text's reality to make it more understandable to their readers. In this case, translators are overmediating, i.e. they think that their mediation should not only be languacultural but logical as well: "The experienced hack may find it quite easy to turn Lermontov's Russian into slick English clichés by means of judicious omission, amplification, and levigation; and he will tone down everything that might seem unfamiliar to the meek and imbecile reader visualized by his publisher" (Nabokov, 1958). 


\subsubsection{Intratext, intertext and realia in poetry}

In poetry, intratexts, intertexts and realia are part of the global poetic strategy. In poetry intratexts are not made of real repetitions only but also of links to words and expressions with a similar sound. As in prose, but more intensely, intratexts form a mixed sound-sense pattern. Intratexts, intertexts and realia often go unexplained in poetry: their implicit nature is matched by the model reader's ability to isolate and decode them.

\subsubsection{Personal style}

\subsubsection{Personal style in psychology}

In psychology, personality is a key component of the psychologist's work. Every one of us has a peculiar style to perceive, store, link and work through percepts. The notion of "style", commonly used by critics in the study of texts, can be applied also in psychology to the subjectspecific way in which a subject chooses to encode and decode perceived reality. Since both the unconscious and the conscious mind use a language consisting of symbols of reality, and the symbolization is idiosyncratic, it is key for the author's interpreter to crack the author's code and to be able to decode it in its idiosyncratic way.

\subsubsection{Personal style in translation}

In translation, there is a set of features that differentiate the author's style from the standards of the given culture or subculture. If the translators know not only the given text but also a significant sample of the whole author's macrotext, they can enact a strategy to preserve the author's style specific features. For example, if you know that Chekhov tends to use two adjectives in a row, without any conjunctions between them, only a comma, you may choose to preserve this stylistic feature also in English, or in any receiving languaculture. You find in Russian "posle žarkoj, dušnoj noči”, and you translate "after a hot, stuffy night", instead of a "after a hot and stuffy night".

\subsubsection{Personal style in poetry}

In poetry, the author's style is something that the authors themselves can use as a parameter to be followed or to be disrupted.

\subsubsection{Cadence and syntactic emphasis}

\subsubsection{Cadence and syntactic emphasis in psychology}

In psychology, shifts in emphasis or cadence mean an inability to adhere to the other's emotionality, to be empathetic with the other. The bottom line sense (denotation) of the text is considered, but the emotional way in which it is expressed is omitted. Intrapersonally, a person who has undergone traumatic experiences often has a disconnection between the verbal and nonverbal, which shows that the memory is not connected to the emotional experience to which 
it is connected - a functional defence that however can become dysfunctional when it is pervasive.

\subsubsection{Cadence and syntactic emphasis in translation}

In translation, shifts in cadence occur when one of the following aspects is altered: punctuation, metrics, paragraphs or rhyme. In all cases the result is an alteration of the oral (or mental, projected from inner discourse) actualization (decoding). The rhythm may result faster or slower, but it is not equal to the original one. When syntactic emphasis in the prototext is altered in the metatext, the emotions expressed in the sentence are altered. Syntactic emphasis has the purpose of stressing where the focus of sense is in the sentence.

\subsubsection{Cadence and syntactic emphasis in poetry}

"What is it about meter and cadence and rhythm that makes their makers mad? (Kaufman, 2002, p. 48)" In poetry, cadence is, alas, what is often lost in translation. Seldom do translators - and publishers - feel the importance of a poem's cadence and set cadence as the dominant of their translation. Cadence is absolutely fundamental in poetry: there is no need to explain why. Cadence is what makes a text a poetic text. In poetry, syntactic emphasis is usually freer than in prose. The subject may be placed after the object or the complements. Any change in syntactic emphasis has a definite sense.

\subsubsection{Indexicality, viewpoint and interpersonal reference}

\subsubsection{Indexicality, viewpoint and interpersonal reference in psychology}

In psychology, deixis (indexicality) has to do with the self-other dialectic. The failure to distinguish the border between the self and other can make it difficult to attribute an emotion to oneself or to the other. It is the same kind of distortion affecting a new-born, who doesn't physiologically know the difference between self and other. Any disruption of the separationindividuation process (Mahler, 1971) may cause deictic problems.

\subsubsection{Indexicality, viewpoint and interpersonal reference in translation}

Translators may tend to interpret deictics as things that have to be psychologically mediated, too. For this reason, sometimes near-deictics are substituted with far-deictics (for example, "this" with "that"). The often unconscious, implicit rationale is that if in a given original situation something was "this", for the translation's model reader, who is "here" and not "there", the same thing will be "that". In this case, the affective mediation (how much something or someone is "near" to the utterer) is considered as part of the languacultural mediation of which the translator is in charge. It's an example of some translators' trend to overmediate: they don't limit their activity to languaculture - they go beyond, feeling the often unaware need to logically mediate as well, as if their model were an "imbecile reader" (see 
2.1.1.2; Nabokov, 1958). This kind of shifts alters the perceptions of the relationships within the text.

\subsubsection{Indexicality, viewpoint and interpersonal reference in poetry}

In poetry, indexicality (deixis) is consciously used as a creative device. The use, for example, of a near-deictic ("e questa siepe"; "and this hedge") has the purpose of forcing the readers' fantasy to feel in the "here and now" what the poet wants them to feel.

\subsubsection{Addressee (register, type of text, displacement)}

\subsubsection{Addressee (register, type of text, displacement) in psychology}

In psychology, there is a difference if the register is shifted upward or downward. If the register is shifted upward, the psychological meaning is a histrionic filtering that needs to alter reality, giving it a more dramatic and bombastic colouring. If the register is shifted downward, the person might have a lower self-esteem, and possibly also an empathically poor perception of the richness and variety of emotions. When patients tell their story, they may displace either a new aim or a new object for goals felt in their original form to be dangerous or unacceptable. Displacement operates unconsciously in the mind, its transference of emotions, ideas or wishes being most often used to allay anxiety in the face of aggressive or sexual impulses.

\subsubsection{Addressee (register, type of text, displacement) in translation}

In translation, a shift of this kind is usually referable to the translator's low sensitivity to differences as to types of readers and types of text. This may be due to a too narrow experience with texts in the prototext or metatext languaculture and their differences. When the translator changes the dominant of a text, we see the homologue of the displacement: for example, in the Italian translations of Pride and Prejudice, irony - which is arguably the dominant of the prototext - is seldom rendered as such and therefore is lost as a translation residue.

\subsubsection{Addressee (register, type of text, displacement) in poetry}

Once, a few decades ago, there used to be a special register for poetry. Contemporary poetry usually uses an everyday register and searches the poetic component without an obligatory register in devices such as word order, sound, contrast and so on.

\subsection{Reality distortions}

In this macrogroup distortions have to do with reality and the different senses (contextual meanings) it may express. In translation, reality is represented by the prototext, whereas in poetry and psychology reality is represented by the poet's or subject's perception: "Various tentative explanations recur to our minds from time to time, and at each occurrence are modified by omission, insertion, or change in the point of view, in an almost fortuitous way" 
(Peirce 1:108). In other words, the shifts within this macro-category tend to modify reality, by adding, amplifying, minimizing or negating some of its features. Some shifts are very strong (like radical changes of sense); some are of a lesser extent (like modulations); others, like calques, have a lighter nature still.

\subsubsection{Radical change of sense (addition, omission)}

Radical change of sense is the random distortion par excellence. Reality is filtered and proposed through a misconception or misinterpretation, without any hint to its inner logics. "Substantially these definitions of composition and aggregation were given by me in 1880 (Am. Jour. of Math. III, 33). They have the effect of reducing all legitimate transformations to successive legitimate insertions and omissions" (Peirce: CP 4.281). "For an omission and an insertion appear to be indecomposable transformations and the only indecomposable transformations. That is, if $\mathrm{A}$ can be transformed by insertion into $\mathrm{AB}$, and $\mathrm{AB}$ by omission in B, the transformation of A into B can be decomposed into an insertion and an omission" (Peirce 4:563). Addition is a process by which someone supplements reality with something else. Omission is a process by which someone deprives perceived reality of something.

\subsubsection{Radical change of sense in psychology}

"While the thought disorder in schizophrenia or more moderate schizotypy is not identical to divergent thinking, there are similarities regarding the tendency to over-inclusive thinking (e.g., delusions)" (Kyaga et al. 2012:7). In psychology, addition, omission and radical change of sense imply a willingness to be the co-maker of the result of perception. You are not only the perceiver/reader of reality, you add to it/subtract from it, pretending that it is more/less than it is - that it is different.

Added reality, or augmented reality, is a misperception of reality in whose view an addition to reality is considered as part of reality. The distortion connected to addition tends to make you think that what you have perceived is more than you actually perceive. The omission bias is a mental device by which inaction is considered more moral than action, even if inaction causes more damage than action. It is a sort of dropping of responsibility, in which the absence of action is mistakenly considered as innocent. Radical change of sense occurs with misperception, while the logic of such misperception is hidden from the researcher. This is the case of misapprehension, in which at least part of the perceived reality has nothing to do with original reality.

When encyclopaedic ignorance is paired with presumption of knowledge, the consequent radical change of sense is connected to overconfidence: the subjects are confident that they know or understand something, and don't fact-check their confidence. In these cases, 
overconfidence is delusional. For other more widespread kinds of encyclopaedic problems, see 2.3 .

\subsubsection{Radical change of sense in translation}

In translation, addition is a process by which translators decide, without any supporting evidence, that the prototext lacks something, and provide the supposedly missing information themselves. Omission is a shift that skips details for apparently no reason. Omission may be justified in the difference between the two cultures when a given detail is obvious in the receiving culture and its omission has the purpose of avoiding redundancy. Omission is often used as a device to overcome allegedly untranslatable elements. Radical change of sense is the least interesting from the point of view of the reconstruction of the effect produced on the receiving culture. There is a shift but it is inexplicable, therefore its repercussions are unpredictable.

\subsubsection{Radical change of sense in poetry}

In poetry, addition is a standard device. Poets are by definition writers who project onto reality their own world, values and thoughts. Reality for poets is a set of symbols (everyday objects are symbolized, prose is transformed into poetry) that are freely interpreted and worked through to produce an explicitly, willingly biased worldview. Omission is a device through which the reader is forced to draw inferences about some parts of the narrative that are not explicated. "What distinguishes the poet or, quite generally, the artist from other human beings, therefore, is not his skill, his mastery, but the intensity of his feeling; and it is this intensity alone which really matters. a work of art produced without feeling, in cold blood, is really a fake; it is dishonest and immoral, for the public is deceived if a poet writes of a love he did not really feel in his heart" (Gombrich 1980, p. 148). Since poetry often draws on unconscious or semiconscious feelings, the poet may use omission as a sort of censorship so as to make their production circulatable. When the poetic text is so randomly different from its real reference that the reader is not able to share the poetic process or understand what the text refers to, a radical transformation of reality has occurred. What outside poetry would be delusional, within poetry is considered as standard practice. Poets often work on the border between psychotic and neurotic worldviews.

\subsubsection{Modulation of sense (specification/generalization)}

In specification, the assumption is that the subjects are optimistic about their knowledge of the subject matter, and are somewhat particular about the needed details. In generalization, the assumption is that the subjects are pessimistic about their knowledge of the subject matter, and are discouraged about the availability of details. 


\subsubsection{Modulation of sense in psychology}

In psychology, specification is a manic, obsessive symptom, while generalization is a depressive, apathetic symptom. A specifying cognition adds details to perception that are not deducted from perception, but inferred on the basis of one's presumption.

A generalizing cognition omits details from perception that are not considered important or useful. This is often the case for depression. Depressed people lose interest in reality, and tend to think that there are no important details to be considered.

\subsubsection{Modulation of sense in translation}

In translation, specification is caused by the assumption that the translator should specify what in the prototext wasn't specified, which implies that they know how and what to specify, i.e. implies a presumption of knowing what is not written and being able to decide whether it is necessary or not to inform the addressee to a greater extent than the prototext's addressee. Generalization is caused by the assumption that the translator is not able to be as specific as the prototext's author, which implies that s/he doesn't know how and what to specify, i.e. implies a presumption of being ignorant about the prototext's external reality and leaving the addressee less informed than the prototext's addressee.

\subsubsection{Modulation of sense in poetry}

In poetry, specification is the cultivation or amplification of details that are inexistent or of little or no importance. On the other hand generalization seldom takes place in poetry, because lyricism is the search for unique descriptions of unique moments. Poetry is a specifying activity.

\subsubsection{Semantic calques}

In semantic calques, a reality feature that is alien and different from one's own is perceived as identical. The projection defence, and confirmation bias, consist in negating the difference between alien reality and one's own.

\subsubsection{Semantic calques in psychology}

In psychology, semantic calques are the consequence of a projection bias. Subjects project the shape of some outer reality feature onto their own mental representation of that reality feature. As a result, subjects think that their own reading of reality is correct, while in fact it is only aesthetically and superficially correct, but substantially biased. The fact that a superficial resonance has recalled a given idea of the sign determines the negligence of its deep semantic sense; the superficial resonance is extended by projection on all the rest, as in the halo effect, producing psychological phenomena such as "love at first sight". 


\subsubsection{Semantic calques in translation}

In translation, a word with external traits similar to another word in the source culture is chosen as a translatant (for example, the Italian word "morbido" ('soft') is chosen as a translatant for "morbid" ("unhealthy'). The difference in the semantic fields is denied or neglected. In the Russian sentence "okno, v kotoroe gljadel kto-to", the Italian rendering 'una finestra dalla quale [lei] stava guardando qualcuno' is a syntactic calque in which the subject ('someone') is mistranslated as the object. As a consequence, the statement is misread and mistranslated and the result is a random bias.

\subsubsection{Semantic calques in poetry}

In poetry, semantic calques are onomatopoeia and rhythm imitation, i.e. poems in which the poet reproduces the outer features of a reality trait through the word sound (onomatopoeia) or the sentence rhythm.

\subsection{Knowledge distortions}

In this macrogroup, distortions have to do with knowledge of data: knowledge of data about the world in encyclopaedias; knowledge gaps owing to reasoning capabilities in logics; knowledge of usage patterns or of subsequent information in anchoring.

\subsubsection{Encyclopaedic and logical presumption}

\subsubsection{Encyclopaedic and logical presumption in psychology}

In psychology, encyclopaedic presumption is connected to the overconfidence bias: the subjects are confident that they know or understand something, and don't fact-check their confidence. In its most extreme cases, overconfidence may be delusional (see 2.2).

\subsubsection{Encyclopaedic and logical presumption in translation}

In translation, encyclopaedic or logical presumption results in mistranslation based on false knowledge of reality, or false judgment about it. Along this line, "Rhode Island" was translated as "Island of Rhodes" by a translator who didn't know the U.S. state's name.

\subsubsection{Encyclopaedic and logical presumption in poetry}

In poetry, encyclopaedic and logical presumption can be creative devices. The poets pretend they know about something, often taking for granted that model readers will read such confidence in the right way: as an artistic device.

\subsubsection{Anchoring, focalism, usage and readability}

\subsubsection{Anchoring, focalism, usage and readability in psychology}

In psychology, anchoring or focalism is a cognitive distortion that describes the tendency to rely too heavily on the first piece of information offered. The final decision is made not out of 
contemplation of the whole set of data available, but negotiating in respect to the first "anchor". This prevents decisions that are on a farther spectrum from the anchor.

\subsubsection{Anchoring, focalism, usage and readability in translation}

In translation, the homologue to focalism is usage. Usage shifts are determined by the ignorance of usage patterns independent of grammar or syntactic rules. There are real collocation customs both within languages and within sublanguages: the translator has to know them, both to abide by them, and to crack them when necessary according to the translation strategy. For example, the German word Weissbier is not to be translated as "white beer", as the first impression suggests, but as "wheat beer", which is what it actually is. Calques are the result of usage carelessness, or of a translatant proposed by a bilingual dictionary, or a casual suggestion. Low readability is the consequence.

\subsubsection{Anchoring, focalism, usage and readability in poetry}

In poetry, usage/anchoring are important factors employed as a reverse device. Generally speaking, usage is employed either to avoid it - poems don't usually follow usage, that's why they are poems - or to abide by it with ironical intent. Consequently, the readability of a poem is typically low.

\section{Conclusions}

After mutually benchmarking categories between different fields, the 20 Valutrad existing categories were reduced to only 10. Intertexts, intratexts and cacophony became one relationship category. From the psychological point of view, cacophony is just another instance of an intratextual - often undesired - link. And intertext and intratext references all belong to the category of links to (inner our outer) texts.

"Personal style" remained the same.

"Cadence" and "syntactic emphasis" were grouped as, in fact, they both refer to the actualization rhythm and, consequently, to the actualizer's emotions.

"Indexicality" is the heir of the former "deixis" category, but substantially everything remains the same. Note that the use of a semiotic category (indexicality) instead of a linguistic one (deixis) allowed the uncovering of interdisciplinary connections.

Finally, "register", “dominant", "displacement" and "addressee" were incorporated. Here, the psychological notion of "displacement" was useful in seeing in a new light the notion of "dominant": choosing a dominant for one's worldview is often a displacement: subjects find an aspect of reality that is particularly interesting to them and displace the text to emphasise it. Since displacement is always functional to a given - real or imagined, projected - addressee, 
the semiotic notion of "addressee" was productive in unifying the framework in this category.

The second macro-category - reality distortions - is paradigmatic of the seriousness of the translation and poetic shifts involved. In translation, in this category we find what were once separately additions, omissions and radical changes of sense. Since Peirce recognized that, from a logical point of view, all radical changes of sense could be decomposed into omissions and additions, this semiotic input allowed simplification of the table.

"Modulation" and "semantic calques" remained the same.

In general, the result of our comparison is that which in psychology and in translation is a distortion that might be corrected in poetry is an important feature of the structure of the text. Intratexts, intertexts and inner rhymes are part of the global poetic strategy. Repetitions are provided on purpose, and cacophony can be a device. Encyclopaedic and logical presumption can be creative devices. Readability is not something that a poet necessarily pursues. Specification is necessary; generalization is absent.

Radical change of sense can be found in poetry, especially in poems by mentally disturbed persons: "Silverman and Will found that when Sylvia Plath shifted her poetic style from a more traditional one to a more expressive or 'confessional' style, her depression grew worse. This provides evidence of the strong relationship between style of writing and an author's emotions" (Thomas and Duke, 2007, p. 216). In this sense, radical change of sense in poetry can be compared to delusional thinking.

Indexicality in poetry is a fundamental trait. If you transform all deictic expressions into rational ones, you get a prose text.

One could say, in conclusion, that any quality that in translation, or psychology, is a distortion, in poetry is a lyrical feature.

\section{References}

Gombrich, E. H. 1980. "Four theories of artistic expression". In R. Woodfield (ed.), Gombrich on art and psychology (pp. 141-155). Manchester, England: Manchester University Press.

Jakobson, R. 1960. "Closing Statement: Linguistics and Poetics". In: Sebeok Thomas A. (ed.), Style in Language. Cambridge (Massachusetts), M.I.T. Press.

Kaufman, J. C. and Baer J. 2001. "The Sylvia Plath effect: Mental illness in eminent creative writers". In Journal of Creative Behavior, vol. 35, no. 1, pp. 37-50.

Kaufman, J. C. 2002. "I Bask in Dreams of Suicide: Mental Illness, Poetry, and Women." In Review of General Psychology, vol. 6, no. 3, pp. 271-286.

Kaufman, J. C., and Sexton, J. D. 2006. "Why doesn't the writing cure help poets?" In: Review of General Psychology, vol. 10, no. 3, pp. 268-282.

Kyaga, S. et al. 2013. "Mental illness, suicide and creativity: 40-Year prospective total population study”. In Journal of Psychiatric Research. vol. 47, no. 1, pp. 83-90.

Mahler, M. S. 1971. "A Study of the Separation-Individuation Process And its Possible 
Application to Borderline Phenomena in the Psychoanalytic Situation". In The Psychoanalytic Study of the Child. vol. 26. pp. 403-424.

Mason, O. J., Mort, H., and Woo J., 2015. "Research Letter. Investigating psychotic traits in poets". In Psychological Medicine, vol. 45.

Maxim, H. 1910. The Science of Poetry and the Philosophy of Language. New York, Funk \& Wagnalls.

Nabokov, V. 1958. "Preface”. In Lermontov, M. A Hero of Our Time. New York, Doubleday \& Company.

Osimo, B., 2013. Valutrad: un modello per la qualità della traduzione. Milano, 9788898467006.

Osimo, B., 2017. “Translation from rags to riches in Jakobson”. In: Sign Systems Studies, in print.

Pandarakalam, JP. 2017. "A Deeper Understanding of Consciousness through Study of Creativity”. In: NeuroQuantology, vol. 15, no. 2, pp. 171-185.

Peirce, C. S. 1931-1958. The Collected Papers of Charles Sanders Peirce, vol. 1-6 edited by Charles Hartshorne and Paul Weiss, vol. 7-8 edited by Arthur W. Burks, Cambridge (Massachusetts), Harvard University Press.

Pound, E. 1912. The Wisdom of Poetry. New York, Forum.

Thomas, K. M. and Duke M. 2007. "Depressed Writing: Cognitive Distortions in the Works of Depressed and Nondepressed Poets and Writers." In Psychology of Aesthetics, Creativity, and the Arts, vol. 1, no. 4, pp. 204-218.

Vygotskij, L. S. 1962. Thought and language. New York, Wiley.

Sofia Adelaide Osimo

Scuola Internazionale Superiore di Studi Avanzati SISSA

via Bonomea 26534136 Trieste Italy

sosimo@sissa.it

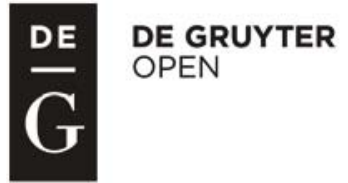

Bruno Osimo

Civica Scuola Interpreti e Traduttori «Altiero Spinelli»

Via Carchidio 220144 Milano Italy

b.osimo@fondazionemilano.eu 